\title{
Reflections on Incentive Regulation
}

\author{
STEPHEN LITTLECHILD*
}

Judge Institute of Management Studies, University of Cambridge

\begin{abstract}
This paper reviews in turn the papers in this Symposium on incentive regulation. It adduces the UK experience with incentive regulation, particularly in the electricity sector, to evaluate, amongst other things, the reasons for development and adoption of this approach, the determinants of setting X, and the case for more advanced metering. It suggests, among other things, that price caps can be designed to facilitate the transition to retail competition, that a rise in complaints might be explicable in part by factors other than quality of service, that TELRIC pricing has yet to acknowledge fully the implications of time and lack of knowledge, and that a failure to recognise the impact of competition on quality and variety of service could underestimate the benefits of competition in supply. It recognises similarities and some differences between the UK experience and the accounts of regulators that have introduced incentive regulation in the US.
\end{abstract}

\section{Introduction}

It is now nearly two decades since the divestiture of AT\&T and the privatisation of British Telecommunications (BT). These events, both in 1984, marked the beginning of more competitive eras in US and UK telecommunications policies. BT's privatisation was accompanied by the introduction of incentive regulation: the so-called RPI-X price cap that had been proposed the year before. ${ }^{1}$ The concept was soon adopted for airports, gas, electricity and water. In the UK we have recently been looking back at how RPI-X originated and at developments since then. ${ }^{2}$

Incentive regulation soon followed in the US, and indeed throughout the world. Indeed there were theoretical and practical signs of it before $1984,{ }^{3}$ but it really took off afterwards. In 1985, 50 US states had rate of return regulation for telecommunications and none had price caps; in 2002, 8 states had rate of return regulation and 38 had price caps. ${ }^{4}$

\footnotetext{
* Mailing address: Judge Institute of Management Studies, Trumpington Street, Cambridge CB2 1AG. Formerly UK Director General of Electricity Supply 1989-98. Email address: sclittlechild@tanworth.mercianet.co.uk I appreciate the helpful comments of Dennis Weisman, the editor of this Special Issue, and Andrew Walker, my former colleague at OFFER now at Ofgem.

${ }^{1}$ Littlechild (1983).

${ }^{2}$ See Bartle (2003), including Littlechild (2003d).

${ }^{3}$ See discussion and references in Joskow and Schmalensee (1986).

${ }^{4}$ Table 1 of Sappington (2003) in this issue.
} 
It is therefore most timely to take a collective look at US developments in incentive regulation, particularly in the telecommunications sector where it has been most actively adopted. The editor of this issue, Professor Dennis Weisman, is to be congratulated on assembling a splendid collection of papers. They provide valuable and thought-provoking information and insights into both theoretical and practical aspects of this phenomenon.

I am honoured to have been invited to comment on these papers. My thoughts inevitably reflect not only my initial involvement in telecommunications regulation but also my last fifteen years practising and commenting on electricity regulation in the UK and internationally. However, there is much commonality across sectors and countries, and I hope that my comparisons will be informative rather than unduly limiting.

\section{Hemphill, Meitzen and Schoech}

The first part of this paper traces the development of incentive regulation in the US telecommunications, electricity, and natural gas industries. The institutional detail nicely complements the tables of changing regulatory frameworks provided by Sappington later in this special issue. The authors find that incentive regulation has grown faster in telecommunications than in electricity and gas. The second part of the paper analyses possible reasons for this.

Among the factors contributing to differences in the adoption of incentive regulation plans across the U.S. telecom, electricity, and gas distribution industries are differences in regulatory commitment and support (including commitment to existing regulation), technological change and productivity growth, industry concentration, service quality concerns, and industry externalities.

\subsection{Regulatory commitment and support}

The authors suggest that the FCC was more committed to price cap regulation than was the FERC, and that the California experience had a dampening effect on the adoption of incentive regulation in electricity. They also suggest that "In contrast to the differences in policy goals and commitment by regulators of these industries in the United States, British regulators established price caps for all three sectors in a relatively short period of time." Actually, the initial price caps were established by the British Government at the times of the relevant privatisations, rather than by the regulators. The regulators did, however, decide to continue with price cap regulation, often in the face of repeated suggestions by various customer groups and commentators (including Parliamentary committees and Government inquiries) that they adopt profit sharing-versions of these price caps.

The authors cite Vogelsang as noting the impediment to the adoption of incentive regulation created by existing rate-of-return regulatory arrangements in the United States. They complement this with examples from Canada. This sounds plausible. I suspect that Australia, and perhaps Norway and Sweden, could be added to the list of countries where there was no existing rate of return regulation to present an obstacle. It is interesting that in one US state (Florida) that has adopted price cap incentive regulation of some electricity companies in place of traditional rate of return regulation, it is the Office of Public Counsel that has taken forward this innovation, rather than the Public Services Commission itself. ${ }^{5}$

\footnotetext{
${ }^{5}$ Littlechild (2003c).
} 
The authors cite Newbery as concluding that "the British approach of regulation by price caps in a legally enforceable contract is also better-suited to the British form of government." (p. 14) He argues as follows:

The British case demonstrates why this [specifying the rights of the utility in contracts] has been the preferred method of specifying regulation. Britain has chosen a high-powered regulatory scheme which is potentially vulnerable to opportunism. Parliament is sovereign and can thus overrule previous legislation, making legislative commitment low. The courts are, however, independent, and well able to uphold the contracts, and the main body of regulation is therefore included in the licences granted to the utilities.

I am not sure that the use of licences in the UK was aimed at deterring legislative opportunism. The (new) Government's decision to impose a windfall profits tax on all utilities demonstrates Parliament's ability to impose additional obligations on all utilities; it could equally have taken powers to change the licenses. Rather, the use of a license reflected a recognition that the details of a utility's regulatory obligations would need to change over time in the light of experience and emerging events. These details could not sensibly be fully embodied in the law, and amendments thereto were best delegated to the regulator. The use of a licence with specified procedures for amending it thus enabled a more flexible regulatory approach rather than precluded it. However, the precise means of making license amendments (by agreement with the licensee or otherwise by reference to a competition authority) was indeed intended to restrict government and regulatory opportunism.

\subsection{Technological progress and concentration}

The authors argue that price caps may be less attractive in electricity because technological progress since the 1970s has been slower in that sector than in telecommunications, and this slower progress provided less scope for new services and cost reductions. Part of the attraction of price caps in all utility sectors of the UK, Australia and elsewhere may have been the scope for cost reductions as a result of the shift from public ownership. The UK experience is that significant cost reductions have now been sustained over a fairly long time period of time - around 15 years in the case of electricity and gas distribution and transmission. Casual observation suggests that there is also scope for significant cost reduction in these sectors in the US.

The authors suggest that the widespread adoption of state price cap plans is partially due to the higher concentration in the telecommunications sector as the large local exchange carriers have pursued consistency in regulation across the states that they serve. An implication is that regulated companies themselves are important determinants of the type of regulation that gets adopted. This theme, which has of course been argued elsewhere, ${ }^{6}$ deserves more exploration in due course.

\subsection{Quality of service}

Concerns about the impact on service quality may have deterred the adoption of price cap regulation in the US (or may have been used as an argument to resist it). The authors rightly note that this was not the case in the UK. Indeed, an important argument for

\footnotetext{
${ }^{6}$ See for example the discussion and references in Peltzman (1989). Donald and Sappington (1997) attempt to explain the choice of regulatory regime in the case of telecommunications.
} 
privatisation of BT had been the expectation that it would improve quality of service. ${ }^{7}$ Subsequent privatisations, particularly of the electricity and water sectors, took explicit steps to maintain and improve quality of service by specifying minimum Standards of Performance. Companies vied with each other not to be at the bottom of the quality of service "league tables", and this in turn facilitated the regulatory specification of higher Standards of Performance over time.

\subsection{Externalities}

The authors mention negative externalities, and concerns that incentive regulation could promote increased energy usage. The latter was a concern to UK energy efficiency groups after electricity privatisation. They were concerned that the average revenue price caps would reduce incentives for energy efficiency and for cooperating with load management initiatives. Although OFFER had some scepticism about the likely magnitude of such distortions, it considered it prudent to convert the transmission price cap from an average revenue cap to a total revenue cap, so as to reduce any artificial incentive on the company to expand output. This was attractive to the transmission company too, since its total output and maximum demand were price inelastic but subject to unpredictable weather fluctuations, and its costs were largely fixed in the short run, so that its revenues and profits were relatively volatile. The total revenue cap brought greater stability of earnings.

By the same token, however, a total revenue constraint had the unintended side-effect of making the transmission price per unit particularly volatile to customers, since a fixed total revenue was divided by a variable total output or maximum demand. ${ }^{8}$ Large users found this unattractive. I was also concerned that guaranteeing a company's total revenue would reduce its incentive to discover and meet the needs of its customers. The regional distribution companies in general wished to retain some linkage between revenue and demand. OFFER therefore moved to a "hybrid" cap for the distribution companies, in which the "driver" was a 50-50 weighting of output and number of customers (that is, it was a 50-50 weighting of an average revenue and total revenue cap). This seems to have proved an acceptable compromise. ${ }^{9}$

\footnotetext{
${ }^{7}$ There was therefore considerable public anger at one early point when standards did deteriorate. The problem was temporary and soon remedied, but it was also severe, to the extent that the chairman of BT resigned over the issue.

${ }^{8}$ It has been argued (Crew and Kleindorfer, 1996 and critique by Comnes et al 1995, ch. 4) that in some circumstances a revenue cap can give a profit-maximizing utility the perverse incentive to set a price higher than the unregulated monopoly level. (With a concave total revenue function there will be two levels of output with equal total revenue: the higher level of output will be the "intended" one while the lower level will be associated with lower costs, higher profit and price above the profit-maximizing level.) However, although there was some academic discussion about possible impact on the output mix, there was never any suggestion that a revenue cap would or did lead to prices above the monopoly level in the UK. Given the inelasticity of demand (at least in the short-run for the duration of the price cap, and with distribution and transmission costs of the order of $33 \%$ and $10 \%$ respectively of total electricity price), the transmission price increase necessary to reduce quantity demanded so as to achieve the constrained level of revenue at the lower level of output would be implausibly large. In any case, the revenue constraint in any year was formulated in terms of the previous year's quantities, so this alone would have precluded the utility from increasing price in the suggested manner.

${ }^{9}$ The authors also mention positive externalities in telecommunications. Whether such externalities indeed exist, or more precisely whether they ought to be used as a basis for setting regulated price caps above or below cost, seems a more debatable proposition. I have argued against it in the case of price caps on UK mobile telephone termination charges (Littlechild 2002a). The editor notes that the existing empirical
} 


\subsection{Uncertainty and separation of businesses}

Is uncertainty regarding cost structure and productivity performance a likely factor that has limited the adoption of incentive regulation in the US electricity and natural gas industries? Such uncertainty depends on the type of business, which brings us to an important factor not mentioned in the paper, namely the greater separation of businesses in the electricity (and gas) sectors in the UK than in the US. In the UK, a distinction has been clearly drawn from the time of privatisation (in electricity and gas though not in telecommunications). Quite separate price controls, and of different kinds, have been set for the different types of business.

On the one hand are the monopoly transmission and distribution networks. The network controls have been strict incentive price caps, on the assumption that costs and productivity are relatively predictable and broadly under the control of the network companies themselves. On the other hand are the potentially competitive activities of upstream generation and gas production and downstream retail supply, activities that take place across the networks. Some of these activities were deemed sufficiently competitive from the beginning, so that price caps were deemed unnecessary and undesirable: this was the case for generation and gas production. For other potentially competitive activities the retail supply businesses - the market was not open initially. The main element of their cost, namely wholesale production or generation costs, was at the time deemed not sufficiently subject to the control of the retail supplier. Strict price caps were therefore initially deemed infeasible for the retail supply controls, which instead provided for passthrough of (economically purchased) generation costs. ${ }^{10}$

US commissions and FERC have generally declined to recognize such separate businesses and to set separate price controls. As a result, regulators would presumably have found it more difficult to commit to a fixed price cap for the business as a whole. ${ }^{11}$ Moves to unbundle the energy sector utilities and to open up markets to retail competition could be expected to facilitate incentive regulation of the network companies. However, such moves seem to have stalled for the moment.

\subsection{Rate rebalancing}

The authors suggest that without any restrictions on rate rebalancing, many distribution companies would base their rate structure largely on monthly fixed access charges, and that these might prove politically unpalatable in terms of an adverse effect on low income users and underpricing of natural resources. This has not been the case in the UK. Distribution businesses have not pressed to structure their charges in any particular way. Supply businesses, being subject to competition, have had no incentive to underprice output. In fact, a notable innovation has been that competitive suppliers now offer tariffs with zero monthly access fee (but higher charge per unit consumed). This was in response

evidence (Hausman et al, 1993) suggests that the access decisions of customers are more sensitive to long distance prices than to local service prices, which implies that subsidizing basic local service from long distance calls actually works against universal service.

${ }^{10}$ OFFER was able to change this approach when the retail supply market was opened to competition. Once customers were able to choose their own supplier it was possible to impose fixed price caps at a level that would cover a supplier's own costs and allow hedging against the risks of generation price movements, as explained in 2.7 below.

${ }^{11}$ Comnes et al (1995) nonetheless describe some US price controls that put fixed caps on distribution costs and allow pass-through of generation/supply costs. 
to long-standing complaints from small users about the fixed charges initially imposed by the previous nationalised industries. So whatever structure of charges the monopoly distribution businesses adopt, competitive suppliers (unless restricted by regulation) will tend to provide whatever structure of charges their customers prefer.

\subsection{Regulatory policy in California}

Since California has been used as a reason for halting or reversing policies of privatisation, deregulation and competition across the entire world, it is worth examining what the authors have to say about this. They comment that "The California debacle was the product of fatally flawed public policy that created, among other things, a disconnect between competitive wholesale electricity markets and regulated retail rates". They are surely correct in this, and in their assertion that "incentive regulation ... was clearly not a primary reason for the industry's crisis". They then say:

The difficulties caused by the wholesale price spikes could have been addressed through a properly structured price cap mechanism. ... the inflation term ("I") in the price cap formula could be based on an index of input prices faced by California utilities. Under such a formula, increases in wholesale electric prices would have led to an increase in the inflation index, and a consequent increase in the price cap (and allowable retail rates)."

I am less attracted by this proposal. Such a mechanism would indeed have alleviated the financial problems faced by the utilities, assuming that it would have been capable of implementation despite the different situations of the companies with respect to any single index of input prices. In effect, it would have redistributed income by placing the burden on customers instead of on the utilities (and to that extent would have reduced demand). However, given that this index would largely pass-through generation costs, this mechanism would have done little to solve any underlying monopoly-related problems, that is, to limit the wholesale price increases, the retail price increases and the consequent political intervention. This is because the index would not have provided better incentives to the parties involved.

It may be more accurate to say that the lack of incentive regulation was a primary reason for the crisis in California. Utilities had no incentive to do other than buy spot indeed, they were positively discouraged from doing anything else, both under the initial price cap and under the subsequent wholesale spot price pass-through policy put into effect in San Diego. As a result, generators had every opportunity and incentive to increase peak prices, utilities had no ability to prevent this, and customers had to pay these prices.

In contrast, a fixed price cap, set (as in the UK) with proper allowance for the cost to utilities of hedging their generation costs over the next two years, would have given the utilities the incentive to hedge while still allowing scope for them to recover their stranded costs, even in the face of competition. ${ }^{12}$ The hedging contracts would have severely reduced the incentives of generators to raise prices, residential customers would have been protected and would not have complained, wholesale prices would not have become a political issue, the State government would not have been tempted into its ill-judged intervention that saddled California consumers with expensive long-term contracts, and retail competition would not have been suspended.

\footnotetext{
${ }^{12}$ For further discussion of transitional supply price caps, see Littlechild (2002b, 2003a).
} 


\section{Tardiff and Taylor}

The first part of this paper reviews recent developments in local competition and local exchange carrier productivity. The proportion of the market supplied by competitive local exchange carriers has grown encouragingly, but the growth of telecommunications output in aggregate has slowed. The authors note that price regulation may need to be refined to recognize differences in the degree and nature of competition, that such regulation should reflect productivity potentials, and that the future health of the industry may well depend crucially on the retail price levels that competition and regulation produce.

\subsection{Setting $X$ factors}

The second part of the paper describes some recent theoretical developments regarding the transition to competition. One of these is the Bernstein-Sappington method for estimating an $\mathrm{X}$ factor for a subset of services of a multi-product firm. Assuming an industry-wide productivity factor, a general rate of inflation, an expected reduction in the price of competitive services, and the share of the firm's output accounted for by these competitive services, this method deduces the appropriate $\mathrm{X}$ factor for the remaining non-competitive services.

The authors point out that when one set of prices is declining more, basic arithmetic dictates that other set of prices will increase faster than the firm's overall average price. This is no doubt correct as a matter of arithmetic, given the assumed data. In practice, prices of competitive services are more likely to reduce faster, at least where competition is effective, because entry is more likely where prices have been held above cost in the past and/or where faster productivity growth is expected in the future. This means that use of this method is likely to require prices of regulated services to rise relative to the firm's average price.

If prices are to reflect costs more closely, this may well be the appropriate outcome. Regulation has tended to cross-subsidize some services by holding down their prices, and these will therefore need to increase in relative terms. However, in order to protect and reassure customers and users of regulated services that these price increases are costjustified, it would seem prudent to check the implied assumptions about the future costs of these services (insofar as joint costs allow). One might thereby calculate (or at least check) the appropriate $\mathrm{X}$ value directly, rather than simply deduce it as an indirect consequence of the projected characteristics of the aggregate and unregulated services.

\subsection{Retail price regulation}

Another theoretical development concerns the necessity or otherwise of retail price regulation following the Telecommunications Act. The FCC Chairman has questioned the case for tightening retail prices, which will squeeze potential entrants. The authors cite several other distinguished economists who have called for retail price deregulation when competition becomes possible.

I sympathise with these arguments. Nevertheless, there are often strong pressures to retain controls "just in case", and even "to save customers the costs of shopping around". There is also some danger in assuming that competition will be effective in practice simply because in theory there are no remaining barriers to entry.

I have argued elsewhere (see previous footnote) that there is a case for leaving a price cap in place for a (short) transitional period, rather than removing it entirely. However, 
during this period the regulator should not seek to revise the cap downwards to reflect achieved or potential reductions in cost. Such a policy would discourage customers from switching to new suppliers, and new suppliers from entering the market. The stated transitional policy ought to be to protect the more vulnerable customers from unwarranted price increases, but to explain that customers generally should look to the competitive market, not to regulation, to bring them the benefits of productivity improvements.

\subsection{Recent developments}

The final part of the paper provides a useful outline of recent developments in incentive plans in five US jurisdictions. In general this paints an encouraging picture of deregulation of business services. The picture is different with respect to domestic (residential) services. It is remarkable that, nearly two decades after the divestiture of AT\&T, and some forty years since the first manifestations of competition in telecommunications, such extensive cross-subsidization and price restrictions still remain. This is, alas, true in the UK too.

\section{Sappington}

Incentive regulation is widely considered to be beneficial in terms of its impact on productive efficiency and hence on price to customers. There is increasing empirical evidence to substantiate this. ${ }^{13}$ However, quality of service is also important to customers. Empirical study of the effects of incentive regulation on quality of service is therefore very welcome, not least because there seem to be some concerns that quality of service may have fallen in recent years. ${ }^{14}$

The author reviews and appraises empirical studies of the effects of incentive regulation on the level of service quality delivered to retail customers in the US telecommunications industry. The main focus is on four studies that use a comprehensive and common data set. His three primary conclusions are 1) that empirical research to date does not provide unequivocal findings regarding the effects of incentive regulation on service quality; 2) that for many dimensions of service quality and many types of regulatory regimes, the empirical research to date identifies no significant impact of regulatory policy on telephone service quality; and 3) that additional research regarding the effects of regulatory policy on the service quality delivered by regulated firms is needed. He offers ten suggestions for how future research might proceed.

Researchers and policy makers are indebted to the author for a most careful and conscientious review. The juxtaposition of the various studies enables us better to understand what each has examined and found, and the initial overview of aggregate developments in quality of supply allow us to see the whole issue in context. It is difficult

\footnotetext{
13 "We review recent studies of the performance of incentive regulation in the telecommunications industry. These studies provide evidence that productivity, infrastructure investment, profit levels, telephone penetration, and new service offerings have increased under incentive regulation. ... Strong evidence that incentive regulation has reduced the costs of providing telephone service has not yet materialized." Kridel et al (1996, quotation from abstract). See also Ai and Sappington (2002). For some UK evidence, see National Audit Office (2002).

${ }^{14}$ This is not to say that previous quality of supply was necessarily at the "right" level. Some would argue that a utility regulated by rate of return would have an incentive to provide excessive quality. However, there is no doubt that customers would be concerned if quality of service were to fall, especially if the level of the price cap had been based on an assumption of constant or improving quality.
} 
to take issue with the author's findings, and his suggestions for future research are fertile, sensible and constructive.

\subsection{The overall picture on quality of service}

The author's conclusions of "no unequivocal findings" and "no significant impact of regulatory policy" may nonetheless suggest that quality of supply has remained unchanged or even deteriorated in some respects as a result of incentive regulation. It may therefore be helpful to explain that the studies in his survey actually allow a slightly more positive record for the US market as a whole over the last decade, including where incentive regulation has been introduced. Consider the following findings on the market as a whole.

- Figure 1 reveals that the percentage of orders fulfilled by the promised commitment date is high (around 99\%). It increased from 1991 to 1992, fell from 1992 to 1999 (especially for business customers), but increased again from 1999 to reach its highest ever level in 2001.

- $\quad$ Figure 2 shows that from 1994 to 2001, the average time required to install a new service has fallen from 3 business days to 1 day for residential customers, and from 4 days to 2 days for business customers.

- $\quad$ Figure 3 shows that from 1991 to 2001 the number of trouble reports declined from 350 to 250 per 1,000 residential lines and from about 170 to 100 per 1,000 business lines. Figure 4 shows that, apart from an unexplained blip in 2000 , the number of repeat trouble reports stayed about constant over this period, at just over 40 per 1,000 residential lines and about 20 per 1,000 for business lines.

- $\quad$ Figure 5 shows that the average time taken to resolve trouble reports fluctuated over time, but overall fell from about 25 hours for residential lines in 1994 to a little over 20 hours in 2001. For business lines there was little net change, varying slightly at around 15 hours, but if anything the time taken had fallen slightly by the end of the same period.

These measures of actual service provided show a somewhat variable but on the whole improving performance with respect to quality of supply over the decade 1991 to 2001. I return shortly to the issue of customer complaints.

What about the specific effects of incentive regulation? The author summarises the results of four main studies in his Table 3. He suggests that:

Table 3 presents a mixed assessment of the effects of incentive regulation on telephone service quality. No systematic impact is evident. A simple count shows six instances in which service quality declines under incentive regulation, four instances in which service quality increases, and six instances where incentive regulation has no significant effect on service quality.

However, closer inspection suggests that much of the apparent differences in results might be explicable by the different time periods chosen (as the author suggests in the context of one of the characteristics). Consider for example the six instances in which service quality is found to decline under incentive regulation.

- Installation commitments met: Study [B] found worse performance. However, it did not extend beyond 1999, the lowest point of performance nationally, especially for industrial customers. Other studies terminated at an earlier year 
before the reduction in performance took effect. None of the studies covered the last couple of years when performance improved significantly.

- Trouble reports: studies [AS] and [C] show deteriorating performance while the other two studies show an improvement. But this component of study [AS] applies to Earnings Sharing Schemes only (which the study treats as equivalent to rate of return) rather than to incentive mechanisms such as price caps. ${ }^{15}$ Study [C] covers only Repeat trouble reports. It starts in the year of improved performance 1992 rather than the previous year of poorer performance in 1991, hence shows a stronger fall in performance later.

- Average time to clear complaints: $[\mathrm{AS}]$ is the only study to find worsening performance, but the study covers only the period to 1996 during which national performance declined. The study does not cover the later period when performance improved nationally. ${ }^{16}$

Thus, the results of the four studies are not necessarily inconsistent with a more encouraging finding that, number of complaints aside, incentive regulation in telecommunications has been characterised by generally improved performance on quality of service over the 1991-2001 decade taken as a whole.

\subsection{Complaints to regulators}

In view of this more positive record, it is puzzling that complaints to federal and state regulatory bodies suggest a different picture. Figure 6 shows complaints rising to a peak in 1995 and to another peak in 2000. But even here the picture is not entirely depressing: the number of business complaints rose only slightly over the whole period 1991 to 2001, and for all customers the number of complaints fell in 2001, to under 30 per 100,000 residential lines and under 10 per 100,000 business lines. The findings by studies [B] and [C] on incentive regulation are not out of line with the national picture over the relevant timeperiods. $^{17}$

These numbers of complaints do not seem excessive compared to UK figures. ${ }^{18}$ Moreover, since the findings on numbers of complaints seem inconsistent with the other empirical findings, it is worth examining the reliability of complaints as indicators of actual quality of service. The UK electricity experience may be helpful here.

\footnotetext{
${ }^{15}$ The number of observations in this study seems to be relatively small - it covers only the short period 1992-96 and only 5 states used earnings sharing schemes in 1996 compared to around 20 states in earlier years. I am not sure whether the number and identity of the states in the sample differed over time or whether there were only 5 observations in total.

${ }^{16}$ The author's Figure 4 does not cover the period 1992 - 94 although that is part of study [AS].

${ }^{17}$ In fact, it is difficult to see how study [AS] finds an improvement from 1992-96 against this general trend. As noted in the footnote above, I am not sure whether the study covers the same companies over the whole period, or whether the coverage varies over time.

${ }^{18}$ In 1998 Oftel was reporting about 50,000 complaints per year. By 2002 that figure had increased to nearly 115,000, of which 62,200 relate to fixed lines, 32,700 to mobiles, 12,900 to Internet and 7,000 to other issues. (Oftel Annual Report 2002, 14 May 2003, 24-5) Complaints for the six-month period 1 October 2002 to 31 March 2003 averaged 30 per 100,000 customers in the fixed line market, 40 per 100,000 in the mobile market and 30 per 100,000 in the Internet service provision market. (Consumer complaints made to Oftel, 19 June 2003).
} 
Shortly after privatisation in 1990 , the number of electricity complaints received by OFFER and its consumer committees was around 80 per 100,000 residential customers. This gradually fell to under 30 per 100,000 by 1998 . Initially, however, the number of electricity complaints increased by nearly $3 \%$ from 1991 to 1992 , even though recorded quality of supply showed a slight improvement. ${ }^{19}$ Our feeling at OFFER was that the increase in number of complaints reflected two factors. First, there was some public and media concern about the principle of privatisation and the real increases in prices that occurred immediately afterwards in first quarter 1992. This may have encouraged customers to complain about their bills rather than about quality of supply. (In fact nearly half of the complaints related to disputed accounts, and only $13 \%$ to supply standards. $)^{20}$ Second, there was increasing promotion of, and an increasing customer familiarity with, the new regulatory arrangements. These were gradually perceived as more effective than their predecessors in dealing with complaints. This too may have encouraged more customers to register complaints with the regulator.

This prompts the question whether the initial peak in US telecommunications complaints in 1995 might have reflected a sense of dissatisfaction that prompted the 1996 Telecommunications Act, or political and media controversy during the passage of that Act, or any rate rebalancing that may have accompanied the introduction of price cap regulation. Alternatively, or as well, did the debate about the Act draw attention to the role of regulatory bodies in dealing with complaints, and did the stance or performance of those bodies in fact change during that period so as to encourage more customers to complain to them? This still leaves open the explanation of the second peak in 2000, which may be related to the sharp but unexplained increase in repeat trouble reports in that year (though the growth in complaints predates that).

Another possibility is that there might be some new source of complaint, for problems not covered in Figures 1 to 5 or only indirectly acknowledged there. The problems underlying the repeat trouble reports must have been extremely frustrating for customers. These problems and the time taken to report them are likely to involve high transactions costs, which should not be overlooked.

It would be interesting to examine the transactions costs of competition more generally - including, for example, the costs to customers of understanding the differing and more rapidly changing prices and of choosing between the ever-changing options available, and the difficulties and time taken to contact and deal with telecommunications companies especially when problems arise (notably the now-familiar but ever-frustrating routing through a sequence of telephone answering machines). ${ }^{21}$ What is the magnitude of these costs? To what extent are they consequences of competition and deregulation in general, or at least of the specific measures mandated by the 1996 Act, rather than consequences of the implementation of incentive regulation itself?

\footnotetext{
${ }^{19}$ Standards of Supply were first instituted on 1 July 1991. The number of payments for failure to meet the Guaranteed Standards fell from 51 per 100,000 tariff customers in the nine-months to March 1992 to 48 per 100,000 in the subsequent year, and continued to fall thereafter. (OFFER, Report on Customer Services 1995/96, Figure 3).

${ }^{20}$ However, most of the complaints to Oftel reportedly relate to quality of service.

${ }^{21}$ The reported service quality measures appear to say nothing about performance on communications. This was initially the case in the UK. However, communications have been a particular bone of contention during winter storm supply outages, when many customers have been unable to report the outages and get information about expected reconnection times. To deal with this, Ofgem has recently made telephone answering times subject to the regulatory incentive scheme.
} 


\subsection{Future research}

The author rightly emphasises the importance of examining the impact of other factors, not the least of which is the extent of competition. He remarks that "economic theory does not even provide unequivocal guidance as to whether an unregulated monopolist will deliver more or less service quality than will a perfectly competitive firm". Surely the more relevant comparison is with a competitive industry, which might be expected to produce a whole range of price-quality combinations? It is not obvious that competition should mean uniform service or a higher quality of service for everyone. Firms in competitive markets should be better able to explore, discover and provide the kinds of alternatives that customers actually prefer (though this process may be difficult initially if choice has never previously been available). ${ }^{22}$

Another critical factor is the extent to which incentive plans refer to quality of service, and the stance of the regulator on this matter (for example, on complaints and public disputes involving telecom companies). As the author recognises (his footnote 22), it is possible that Standards are introduced precisely where quality of service is lowest. Without adequate qualification, a cross-section study might wrongly appear to indicate that Standards tend to reduce rather than increase the quality of service.

The UK experience suggests that uniform auditing of data is important: despite uniform guidelines, different companies tend to interpret and record information in different ways. As more weight is placed on this factor, Ofgem has taken more steps to ensure auditing and consistent reporting. There have also been examples in the UK electricity distribution sector where a closer regulatory focus on quality and better monitoring has appeared to lead to a reduction in quality of performance. However, the firms concerned have explained that this has simply reflected more accurate reporting.

\section{Sherman}

The author examines the interplay between the carrot of profit seeking and the stick of competition. He notes that these have been introduced to traditionally regulated firms through the use of price cap regulation. His focus in this paper is on the restructuring of industries with a view to increasing the efficacy of the carrot and stick.

\subsection{Price caps and technical progress}

The author rightly notes that in practice price cap regulation comes with complications. "Estimating the potential for technological progress can be especially difficult in newly privatised industries, yet it must be done in advance as part of the basis for the price cap." This is true, and some expositions place major emphasis on technological progress.

Yet technological progress narrowly defined usually plays a relatively minor role in setting price caps in newly privatized industries (with the possible exception of telecommunications). More important in aggregate are a variety of other factors such as the

\footnotetext{
${ }^{22}$ The editor raises the question whether regulators should be encouraging different price-quality combinations since these would arise in competitive markets. In some cases (as in a given area of a distribution network) the technology may make this difficult. It is also difficult for a regulator to justify different qualities of service to different customers. The greater variety of outcomes that would emerge under competition is a less tangible but nonetheless important benefit of deregulation.
} 
extent of inefficiencies in the business at present and the scope (managerially and politically) for reducing these, the extent to which prices exceed or fall short of costs and the commercial and political scope for modifying them, the need or otherwise to reduce or maintain or even increase cross subsidies, the likely changes or variability in input prices, the extent to which competition is to be allowed and the predicted rate at which it might develop and the impact that it might have on outputs and cost recovery, the requirements of the stock market in terms of profits, profit growth and financial ratios, the extent to which prices at the end of the price cap period are expected to be sustainable thereafter, and so on.

One might wonder whether such factors disappear after privatisation, so that a relatively simple formula for setting price caps might be adopted. However, in my experience these or similar factors continue for some time. Newly privatized industries, and to some extent newly deregulated ones too, tend to have been isolated from many economic pressures and are far from reflecting an efficient and stable economic structure. Whether even industries that have always been privately owned can be characterized by a stable rate of technological progress is a debatable point.

\subsection{Access pricing in telecommunications}

In the context of restructuring telecommunications, the author suggests that "two main ideas guide access pricing", namely the efficient component pricing rule and Ramsey pricing. In varying degrees these are popular with economists. I must confess that I found it difficult to summon up much enthusiasm for either. I could not quite see how to explain to users of a monopoly service that building the present level of profit into a regulated access price was a good idea. However, I note that Baumol (2001, p. 154) has helpfully clarified that regulated prices must yield no monopoly profits.

I would also have found it difficult to explain to customers with the greatest need or fewest alternatives (as measured by inelasticity of demand) that for these reasons the price to them would be higher. This, rather than the difficulty of estimating the differences in elasticity, was the obstacle to adopting this policy. But it is fair to say that I was not faced (or did not think I was faced) with situations that called for these kinds of pricing. I wonder if I would have thought differently if I had been regulating telecommunications, where such concerns mainly seem to surface. I note that Gifford's regulatory commission had similar reservations.

\subsection{Retail competition in electricity}

The author explains that one of the reasons why retail competition has not been a great success in the US is that residential electricity consumers were favoured by low regulated rates. Prices to residential customers might rise with restructuring because costs for residences are higher than the previous regulated prices would indicate.

I am not sure of the precise cost and price relativities in the US, but I suspect this is probably true. Indeed, it seems to me that one of the less tangible (and not always appreciated) merits of deregulation, and in particular of restructuring, is that it makes more apparent the structure of costs that was previously almost entirely hidden. A notorious example in the UK is the nuclear program, promised to produce electricity "too cheap to meter", which turned out to be too expensive to privatize. Restructuring, competition and private ownership put in motion a process not only for identifying but also for reducing costs where possible. This proved remarkably effective, and also enabled a nearly $50 \%$ 
increase in output, although for various reasons the future of the nuclear stations are again in doubt at the time of this writing.

\subsection{Fluctuations in demand}

The author suggests that "residential demand fluctuates more than commercial and industrial demands, and for that as well as other reasons residences tend to be more costly to serve." These "other reasons" soon became apparent in the UK. Residential consumers had more peaky loads at times of system load factor when generation prices were high. They had higher distribution costs because they used all voltage levels of the network whereas industrial customers used only high voltage levels. And they had higher supply business costs because the costs of metering and billing them, and dealing with customer inquiries and complaints, were very much higher on a per unit basis.

Residential demand may fluctuate more than many commercial and industrial demands, both over the day and particularly with the impact of television programs within any half hour. Ironically, however, customers are not charged extra for the costs of any fluctuations in their demand. In the UK, each supplier is charged for the average level of electricity consumed by its customers during each half hour. Whether that level is constant, rising or falling within the half hour, whether it is smooth or spiky, whether it is predicted or unpredicted, whether it is the same or different from one half hour to the next - all these factors seem to be irrelevant from the point of view of costing and charges. ${ }^{23}$

There is a case for looking at this again. Present arrangements are perhaps explicable in terms of simplicity, and minimizing metering and billing costs. However, the costs to the system operator of preparing for and responding to spikes and troughs in demand (and sudden failures in generation) could be very significant. Surely the charge for electricity should reflect not only the level of consumption in each hour or half hour, but also the variability or range of consumption within that half hour. This would reflect more accurately the relative costs of supply of different classes of customers. It would provide a greater inducement to predict and control fluctuations in demand and generation, and there would probably be a deeper market for the services of fast response plant (and demand side responses).

\subsection{Metering}

Charging according to the range or volatility of consumption would also provide a further much needed but justifiable boost to more advanced metering. I say a "much-needed boost" because I fear that the present economics of metering do not generally justify installation of the time-of-day metering that the author goes on to discuss. Several economists have advocated such metering, and illustrated the potential benefits. However, I have yet to see a detailed economic evaluation showing that such benefits outweigh the prospective costs.

I was keen to encourage developments in metering at OFFER. However, the rough calculations we did suggested that, although the costs of time-of-day meters were not much higher than those of routine meters, the costs of installing and using the communications facilities to take advantage of these meters was quite considerable. Bulk purchasing and installation on a national scale could perhaps reduce costs. But was it sensible for a

\footnotetext{
${ }^{23}$ I suspect this is the case in other countries as well, although New Zealand's five minute calculations may be an exception.
} 
regulator to dictate the type and installation rate of such a fast-changing technology, knowing that whatever the regulatory choice it would probably turn out to be wrong in the light of subsequent developments?

Would time of day meters indeed lead to more elastic demand on the part of residential customers? Experience with large and medium-sized users who do have half-hourly meters does not suggest that many of them find it economic to take electricity on a spot price basis and to vary their demand in response to price. The most popular type of pricing seems to be a single price per unit with some limited facility for load management at times of system peak. It is possible that automatic control devices could make residential demand more responsive (for example, by cutting out electricity to deep freezers for an hour) but to install such devices would add further to the costs.

Nevertheless, the author is right that "the pace of innovation in the telephone industry is remarkable today, and would probably not have been matched by the old regulatedmonopoly regime." The same is surely true of electricity. There is still hope for exciting developments in metering in due course. But I suspect that the development of pricing and contracting arrangements to meet variations in demand will have an earlier payoff.

\section{$6 \quad$ Mandy and Sharkey}

The Telecommunications Act of 1996 aimed, among other things, to open local telecommunications markets to competitive entry and to deregulate where regulation was no longer necessary. The Federal Communications Commission (FCC) has implemented the Act by adopting a new regulatory pricing standard known as "Total Element Long Run Incremental Cost" (TELRIC). ${ }^{24}$ This has caused some concern.

TELRIC has been used to price unbundled network elements and interconnection, and has been widely criticized both as a conceptual framework and as actually applied by regulators. An underlying current in many of these criticisms is the static nature of TELRIC pricing as implemented to date, when actual telecommunications industry costs are highly dynamic. ${ }^{25}$

The paper considers how TELRIC pricing can be correctly implemented in a dynamic environment. It shows how prices that are periodically reviewed can be calculated to recover the cost of a given investment in physical equipment. It also shows how to derive the investment plan and utilization path as the solution to a cost minimization problem, under assumptions about demand growth and input costs.

When investment costs are falling over time and TELRIC price reviews are conducted at intervals shorter than expected asset lives, a firm will earn less than its target rate of return under the TELRIC methodology as generally implemented.

... it is possible to compute a correction factor based on estimates of the rate of change of investment cost and the expected time between TELRIC reviews. Corrected TELRIC prices rise or fall at the same rate over time as underlying investment cost, and allow the firm to earn its target rate of return no matter how frequently price reviews are conducted. ${ }^{26}$

\footnotetext{
${ }^{24}$ Rather surprisingly, the paper itself contains no definition or explanation of TELRIC that would enable the reader to judge how far a particular calculation or methodology is consistent with it.

${ }^{25}$ Criticisms of TELRIC pricing can also be found in some other papers in this collection, for example, Hazlett and Havenner, and Gifford.

${ }^{26}$ Essentially, the correction factor is the ratio of the required revenue to the revenue that would otherwise result. (It is perhaps unfair to call this a correction factor, since the calculation that takes proper account of potential future reductions in cost does not need such a correction).
} 
I feel a sense of nostalgia on reading this paper. When I first met Bill Sharkey in the late 1960 s, I too was working on mathematical models for pricing and investment in public utilities, especially in telecommunications. Models developed at that time enabled a better understanding of the relationship between prices, costs and depreciation. ${ }^{27}$ The present paper rightly emphasizes a point established then, that the faster is the rate of technological progress and cost reduction in the future, the higher is the marginal cost of increasing output and investment now. The present paper also assumes, again rightly in my view, that the advantages of allowing regulated prices to cover total costs, at least in prospect for efficient operation, outweigh the advantages of setting price equal to marginal cost where this would lead to operating at a loss.

\subsection{Dynamic efficiency and the passage of time}

However, the paper runs up against the same kind of difficulty that discouraged me from further work along these lines. How to deal with the passage of time, and the changing costs and information that are a necessary consequence of the passage of time?

The paper refers to "dynamically efficient investment plans". By this, it means plans that are efficient as appraised today, given a specified set of assumptions about future costs, technology, demands and other parameters. The latter are assumed to change over time, as indeed is plausible, rather than to remain constant. However, the ways in which they will change are assumed known. All TELRIC prices are therefore calculated as of time zero, including the TELRIC prices that would be calculated at future periods by the regulatory commission. Time itself does not move on. The model does not look at the situation as it might be after time zero. In practice, however, the passage of time has two important consequences. ${ }^{28}$

The first consequence is that, even if predictions about the future are entirely accurate, opportunity costs change. Once the investment is made, the opportunity costs of production are changed, and are typically lower. This is because the cost of the investment is now sunk, and the opportunity cost is simply that of the variable inputs required to produce output. In general, this presents a dilemma. Prices set at time zero continue to recover total costs but no longer reflect opportunity costs. But prices that change to reflect opportunity costs no longer recover total costs.

If I understand correctly, TELRIC prices seem to avoid this dilemma because they are not claimed to reflect the actual opportunity costs faced by a particular firm at any particular time. Rather, they reflect the costs that would be faced by a hypothetical efficient firm at any point in time. As such they are independent of the actual investment made by the regulated firm, and continue to recover total costs, at least as foreseen at time zero.

However, this does not overcome the second consequence of the passage of time. In reality, things never turn out precisely as expected. It is impossible for a regulator, or anyone else, to predict with complete accuracy the future path of costs, technology, demands, and other relevant parameters. It follows that TELRIC prices, as set at time zero and as assumed to be recalculated at intervals into the future, will fail to recover total costs exactly. They will under-recover or over-recover costs according as the regulator underestimates or overestimates the future rate of cost reduction. Future cost is not the

\footnotetext{
${ }^{27}$ For example. Littlechild (1970) and Baumol (1971).

${ }^{28}$ There are other consequences as well, as discussed below in the comments on Hazlett and Havenner.
} 
only parameter, of course, but except by a remarkable coincidence in which forecast errors just cancel out, it will normally be the case that TELRIC prices will fail to recover total costs exactly.

\subsection{Dealing with time}

There seem to be at least two ways of dealing with this. One is to apply a series of correction factors, recalculated over time in the light of events, so that the continually corrected TELRIC prices do indeed recover the costs that were assumed to be efficient at the time when the investment was agreed upon. In effect, customers are required to cover the costs of the initial forecasting errors inevitably made by the regulator.

The other way is to recalculate TELRIC prices at each review period, based on the parameters actually obtaining at those times - or more precisely the parameters expected to obtain from those times henceforth. This abandons any commitment that TELRIC prices should cover actual costs of actual investments. In effect, regulated companies rather than customers are required to cover the costs of the forecasting errors inevitably made by the regulator. (No doubt there would be discussion as to how far the companies themselves also made or should have accepted these errors.)

The latter interpretation may seem more consistent with the TELRIC methodology, if the aim is faithfully to reflect projected future costs of a hypothetical efficient firm as assessed at the time of each review. However, imposing the risks of forecasting errors on the regulated firm has other consequences that need consideration. Importantly, it means that the risks faced by the firm are higher than they would be under the alternative approach. This has implications for the cost of capital, although the authors eschew discussion of this issue.

There are also possible implications for competition. The authors indicate that one of the goals of the Telecommunications Act was to open the market to competition. Presumably one of the aims of the TELRIC approach was to ensure that competitors using network services provided by incumbents should not be at a competitive disadvantage. They were to be charged no more than the cost that would be incurred by an efficient firm operating under the latest assumptions about the relevant parameters.

Some have challenged the validity of this argument, suggesting various reasons why incumbents might not have a reason to overstate the costs of access to their network. ${ }^{29}$ In the context of UK electricity distribution companies, there seems to have been a fairly unambiguous incentive to allocate costs to the (monopoly) network rather than to the (competitive) retail supply business. ${ }^{30}$ If accepted by the regulator, this would mean higher network revenue and less scope for entrants to undercut the incumbent in the supply business. In the 2000 price control review, Ofgem reallocated to the supply businesses an average of about $8 \%$ of costs that the incumbents previously classified as network costs.

However, the point I make here is a different one. If TELRIC pricing means that regulators review costs at periodic intervals and revise allowed charges accordingly, this will mean a corresponding degree of uncertainty about what future charges will be. Competitors will therefore be vulnerable to the forecasting assumptions and errors of the regulator. They will be less able to predict what their costs will be than if the regulator fixed these charges for the life of the relevant assets or, which may amount to the same

\footnotetext{
${ }^{29}$ For example, Weisman (2000).

${ }^{30}$ With very limited exceptions, there is no significant threat of entry into the network business, and no scope for the network to compete in other areas or activities.
} 
thing, if the regulator allowed the network owner to recover the costs of these assets under assumptions that held at the time when the investment was made.

Although this paper responds to one of the concerns about TELRIC pricing, it does not seem to come to terms with the limited knowledge of the regulator in a way that incentive regulation does. I suspect that TELRIC policy is not quite out of the woods yet.

\section{$7 \quad$ Hazlett and Havenner}

This paper expresses concern about the policy of mandating network sharing as it has been implemented in the US telecommunications sector. It notes the various arguments that this could stimulate competition and also that it could provide a disincentive to new investment in network facilities. But whereas the previous literature has suggested that this is essentially a wealth transfer between incumbents and entrants, this paper argues that both entrants and incumbents lose from the resultant competition.

The FCC's TELRIC policy is alleged to suffer from this defect.

This standard attempts to impose prices equal to a pro rata share of what a new, state-of-the-art, efficiently sized system would cost to construct. Because technology improves over time, the cost of network investment elements should predictably decline under TELRIC rules, which do not reflect the investment or technology decisions embedded in the incumbent's actual network. ${ }^{31}$

There seems to be some dispute as to the appropriate characterization of TELRIC rules, and whether other aspects of the existing network are to be taken as given, ${ }^{32}$ but this is beyond the scope of the present review.

\subsection{Network sharing rules}

The paper then describes the debate about network sharing rules, particularly those that focus on the list of unbundled network elements that can be rented from incumbents at regulated rates, and on the levels of those rates. The "pro unbundling" position emphasises the advantages to entrants through economies of scale and through "stepping stones" to offset the advantages of incumbency. The opposite position emphasizes the disincentive to incumbents to invest in network improvements.

There is merit in both of these positions. A merit of the first position is that it recognises that competition does not take place in a purely static world. It is not simply a matter of optimal resource allocation in light of known costs and prices. One of the arguments for more extensive unbundling rather than less is that it helps, over time, to reveal the costs of the different components of cost that could otherwise remain obscure. This is of assistance to regulators, entrants and even incumbents themselves. Several UK companies, most notably British Gas, have chosen to break themselves up in order to increase their effectiveness and market value.

An additional merit of this position is the recognition that entrants are subject to very considerable cost and risk. If entrants are able to tackle some aspects of the entry process while deferring others (for example, are able to produce some components of service while buying-in others that are more difficult to produce) this will assist entry and thereby facilitate the growth of competition.

\footnotetext{
${ }^{31}$ The authors footnote that "The one exception is that the geographical pattern of central offices in the incumbent's existing network is employed in estimating TELRIC prices."

${ }^{32}$ For example, Weisman (2000).
} 
These considerations were important in opening the UK electricity market to retail competition. OFFER ensured that entrants could buy from incumbents all those services such as meter reading that would otherwise make new entry difficult or impossible. The regulated price put on any one component at any time was perhaps less important than the separate identification or unbundling of all relevant components.

At the same time, concerns about the level of component prices are by no means misplaced. Hausman and Sidak (1999, p. 58) argue that cost-based pricing such as TELRIC forces incumbent network owners effectively to offer free options in new investment to entrants. The latter will take up the options if the investment succeeds and not if it fails. This can put undue costs and risks on the incumbents. In particular, it is suggested that the assumptions underlying the setting of the wholesale price have underestimated the extent to which business is lost, or have failed to take account of this at all, to the extent that previous or further investment is rendered unprofitable.

This too was a consideration in opening the UK electricity market. For example, in setting transitional retail price caps on incumbent suppliers, OFFER was careful to take account of any impact of their likely loss of market shares on their customer costs. The price cap was to that extent higher than it otherwise would have been, which removed any suggestion that incumbents could not profitably provide such services, and at the same time facilitated the entry of new suppliers.

\subsection{Costs of rent-seeking}

The central argument of the paper is "a paradox seemingly overlooked by either side".

In mandating network sharing rules ... the incumbents' costs are not transferred to entrants, who enjoy non-exclusive option rights. Instead, a rivalry to capture profit opportunities is triggered due to minimal barriers to entry - precisely the intention of the policy. ... Hence, the relevant competitive margin becomes marketing. Incremental customer acquisition costs rise until, at the margin, profits are zero.

This is not the result one expects in competitive markets generally. There, lower input prices may be assumed to lead in due course to lower output prices, greater output and benefits to consumers.

What assumption in the present model generates this rent-seeking behavior that seems to have no beneficial effect? It seems to be the assumption that demand, and hence the value of output, is somehow given, entirely independent of the advertising and marketing activities that are the focus of the paper's analysis. On this basis, advertising and marketing competition serve merely to reallocate customers between competitors, with no net benefit to the customers.

This assumes, in turn, that the nature of the service provided is somehow given, independently of the extent and nature of competition. Competition has no beneficial effects on the nature and variety and quality of the services offered, on learning by customers about the options available and on learning by companies about the preferences of customers, and on the process of innovation. In practice, however, the competitive process in telecommunications, electricity and gas supply has yielded significant benefits of these various kinds. ${ }^{33}$

\footnotetext{
${ }^{33}$ For example, Littlechild (2002b) for the UK electricity market.
} 


\subsection{Stock market evidence}

The third section of the paper discusses stock market reactions to two key events. The first is a news story in January 2003 that the FCC would relax its unbundling policy; the second is the subsequent announcement in February 2003 that the FCC would maintain and actually extend its unbundling policy. The authors note that the share prices of relevant stocks - incumbents, equipment manufacturers, and competitors - varied in response to the first announcement but fell on the second announcement. They seem to interpret this outcome as confirming their hypothesis that the FCC policy made market participants worse off or at least no better off.

This is a fascinating series of events, and in due course a formal and comprehensive statistical event-study of the whole period will be illuminating. It would seem useful to examine the impact on customers as well.

\section{$8 \quad$ Vasington}

The Massachusetts Commission approved a six year incentive plan for Verizon in 1995. This comprised an "Inflation - X" price cap index with adjustments for exogenous costs and service quality, and no provisions for earnings measurements or sharing. This paper is a case study of what preceded the plan, how the plan was decided, and what came after. It is a most valuable description and evaluation, shedding further light on how regulation actually operates, what the pressures and tradeoffs are, and what lessons might be learned for the future.

The Verizon plan resulted from an invitation from the Commission to the company to propose an alternative form of regulation, which it did. This relatively passive approach seems to have characterised US state regulation. In contrast, almost all significant developments in UK utility regulation have probably originated with the regulatory body.

\subsection{The level of $\mathrm{X}$}

The determination of the level of $\mathrm{X}$ is interesting. Verizon proposed 2.5 per cent, comprising a 2 per cent Total Factor Productivity (TFP) differential (that is, the difference between productivity in the telecommunications sector and in the economy as a whole) plus a 0.5 per cent consumer productivity dividend. The Attorney General (the Massachusetts consumer advocate) argued for 6.2 per cent, comprising a 2.6 per cent TFP factor, a 2.6 per cent input price differential and a 1 per cent consumer price dividend. The Commission decided on 4.1 per cent, comprising a 2 per cent TFP factor, a 0.1 per cent input price differential, a 1 per cent consumer productivity dividend, and a 1 per cent "accumulated inefficiencies" factor. ${ }^{34}$

In the UK, the initial $\mathrm{X}$ factors were determined by the Government (as shareholder) at the time of privatisation. They were set at the same time as the initial financial structures, with a view to balancing the ability to pay an acceptable stream of dividends against the

\footnotetext{
${ }^{34}$ The consumer productivity dividend is not explained - insofar as it reflects an expectation that productivity will be higher in future than under rate of return regulation, it is not clear how it is distinguished from the TFP and "accumulated inefficiencies" factors.
} 
need to demonstrate benefits to customers. Later X factors ${ }^{35}$ were set by utility regulators, with a view to protecting the interests of customers while ensuring that companies could finance their licensed activities.

Both sets of calculations have generally reflected a financial model of the next five years or so, embodying assumptions about the scope for reductions in operating costs, the size and timing of the capital expenditure program, the cost of capital and the implications for various financial ratios. It is possible to trace the relationship between $X$ and the separate assumptions on cost and capital expenditure etc, but this is not so explicit as in the US. The utility will accept (or reject) the values of $\mathrm{X}$ and Po as a whole, including any quality of service or output targets, without committing to the particular assumptions underlying them.

In both countries there is evidently a substantial amount of regulatory judgement as to the appropriate total value of $\mathrm{X}$. The author seems uncomfortable with this: "Mistakes that were made in the Verizon plan include the creation of an accumulated inefficiencies factor in part to bring the productivity offset in line with other states". What specifically is the mistake here? If it is the concept of an accumulated inefficiencies factor, would it have been preferable to leave the company with the entire benefits of eliminating the inefficiencies of its previous regulated existence, rather than to share this with customers? If it is the reference to the actions of other states, is it not relevant and helpful to look at what efficiency improvements and what balances between customers and investors have been considered plausible in other jurisdictions, in the light of the responses of investors and the actual achievements of managements in these states?

Perhaps the concern is the practical problem of demonstrating inefficiencies. The burden of proof may be higher in the US, where it has to be shown that a cost in the test year (typically already incurred or soon to be incurred) is unreasonable. In the UK it is generally sufficient to argue that the assumed scope for future cost reduction over a period of years is not unreasonable. Admittedly determining a reasonable level for this assumption is difficult and subjective, but evidence from past performance, from other companies both within and outside the sector, and indeed from other countries, can increasingly be brought to bear on the decision.

OFFER found it helpful to bring in a panel of three very senior and respected businessmen to advise on what it would be reasonable to expect of each regulated company in the way of increased performance. One of them expressed his view on the package ultimately proposed: "I think this would be a nice challenge for the company." Though economists naturally seek objectivity where possible, we should not forget that businessmen themselves continually have to make subjective judgements of this kind. ${ }^{36}$

\subsection{Quality of supply}

The Verizon plan included penalties for reductions in service quality but no rewards for above average performance. A later plan for another electricity company included such an incentive. The author classifies the absence of a reward in the Verizon plan as a mistake.

\footnotetext{
${ }^{35}$ OFFER accompanied its X factor by an initial price reduction Po which has been followed by many other regulators.

${ }^{36}$ This also seems to be the basis on which stipulations have been agreed between the Office of Public Counsel and various utilities in Florida, which agreements have subsequently been ratified by the Public Services Commission. (Littlechild, 2003c).
} 
This is perhaps too harsh. It is not straightforward to identify the relevant dimensions of quality, measure them and calibrate a quality incentive, especially given a lack of knowledge about the ability of a company to respond and the preferences of customers as between quality and price. Deferring such a quality incentive until experience has been gained with a first price cap seems a sensible step. The UK experience suggests that a lot can be achieved simply by measuring and publishing performance against specified Standards, with relatively small compensation payments.

\subsection{Sharing and calculation of earnings}

The Commission decided against earnings sharing, for several reasons: it did not want to introduce cost-of-service disincentives to efficiency, it did not want to have to rule on the prudence of investments underlying the costs and earnings, and it thought that an annual review of earnings would necessitate a significant administrative burden. All these are plausible arguments that have so far been persuasive to UK regulators. But the Commission went further:

The Commission decided that it did not even want to see a calculation of the company's earnings...

The primary reason for not even calculating earnings was to avoid the temptation to recontract the

plan. ... Having decided that reported earnings were largely irrelevant to an evaluation of the plan, the commission did not want to see them calculated during the duration of the plan.

This seems a bolder step. It is certainly important to resist recontracting the plan during its agreed duration. However, it would have been difficult if not impossible to resist calculating earnings in the UK - or more precisely difficult not to publish the relevant regulatory accounts from which the earnings could presumably be calculated. UK customer groups were much exercised as to whether the regulatory judgments underlying the calculation of X factors were "correct" or at least reasonable. They wanted to track the performance of the companies against the assumptions made by the regulator. Indeed, the format of the published regulated accounts was actually revised to facilitate this. ${ }^{37}$ Recently, Ofgem has indicated an intention to make greater use of annual information as a means of reducing the burden of information provision at the periodic resetting of the control.

\subsection{Other issues}

The author gives a valuable account of the annual filings during the six years of the plan. It is entirely to be expected that issues will arise that were not previously considered in setting the price cap. Sometimes these can work against the interest of the company and make the price cap seem unreasonable. An example is the unintended provision that subperformance on service quality in only two years penalised the company in all subsequent years.

The author's defence by analogy with employee remuneration is not entirely persuasive. Would poor initial performance really hold back an employee who subsequently attained acceptable performance? A concern to maintain parity of payment for comparable performance would surely lead an employer to amend the situation at an

\footnotetext{
${ }^{37}$ What inferences should be drawn from these comparisons is of course debatable. If costs are lower than projected and profits higher, did the regulator set the $\mathrm{X}$ value too low or did the firm respond as intended to the incentive regulation?
} 
early opportunity after acceptable performance was achieved, even without subsequent above-average performance.

It seems to me that non-adjustment of the contract to remedy an apparent oversight has to be justified on the grounds that what one party loses on the swings it may gain on the roundabouts, and that "correction" of the contract on one issue would set an unfortunate precedent. Since price cap arrangements are difficult to amend before the end of their term, this is a relevant factor to take into account in deciding their duration.

The author explains the difficulties caused by a regulatory price freeze locking in inefficient rates for residential services. His classification of this as a mistake is more convincing. It is, alas, a fairly universal mistake, even from the perspective of those whom it is intended to protect, since it tends to restrict competition wherever it is practiced. In many countries overly tight price freezes are effectively precluding the private sector from offering customer choice and greater efficiency.

\section{$9 \quad$ Gifford}

The aim of this paper is summed up in one succinct paragraph.

Instead of a formal model, I propose a description about how state regulatory commissions operate and how decisions are made. It has none of the analytical firmness of, say, an interest group capture or the self-aggrandisement model of regulatory behavior. But I think the description more fully captures the texture of regulatory decision-making and activity at the state level. If accurate, then this description will suggest the roles state regulatory commissions ought and ought not to play into the future.

The author achieves this aim splendidly. It is a paper of which Nobel Laureate Ronald Coase, whom the author cites approvingly, would be proud. Here are no "blackboard economics". Here are "regulatory institutions as they are, not as they should be, or divorced from what they actually are".

The author's description and analysis are persuasive. His Colorado/US regulatory commission is in some ways reminiscent of the UK Monopolies and Mergers Commission of which I was a member for six years. In both cases "proceedings are characterised by an enormous volume of information". Yet in the UK each member was able to concentrate on at most two or three cases for six to twelve months at a time. How much more difficult must it be for a US regulatory commissioner to cope in addition with the regular agenda of a regulatory commission.

Information costs, information asymmetry and - given a broader agenda - opportunity costs swamp the ability of a regulator to give careful attention to each and every matter.... These, then, are the fundamental realities of the state commissions: limited resources, time, and experience; enormous legal discretion and breadth of task; and haphazard competence.

\subsection{Replicating a competitive market}

The author's description of "what regulators cannot do" should give pause for thought to those who assume that regulation can and will remedy market failure. ${ }^{38} \mathrm{He}$ points out that regulators constrained monopoly pricing, but only "at the cost of gold-plating and desultory innovation". Their task is said to be "mimicking the outcomes of a competitive market" but "how do you mimic a market when one does not exist in the first place"?

\footnotetext{
${ }^{38}$ For a further example of the limitations of regulatory behavior, see Littlechild (2003b).
} 
Marginal cost pricing can lead either to bankruptcy or to monopolistic and socially unacceptable Ramsey pricing. In practice, regulators have instead been led to design rate structures to serve social and political ends.

It is said that "regulation should seek to emulate a competitive market outcome and that prices should be based on marginal cost". ${ }^{39}$ OFFER's regulation of the UK electricity market did not try to do either. Weisman has well summarised the problem with the first aim: it "confuses mandating the competitive outcome with fostering the competitive process". ${ }^{40}$ How can a regulator simulate a discovery process? Where competition was plausibly possible OFFER sought to encourage it, not least by removing price controls. Where competition was not plausible OFFER sought to incentivize the incumbent monopoly.

Marginal cost was a potentially relevant consideration in a competitive market, but OFFER resisted the suggestion that competitive prices would be precisely equal to marginal cost if this meant not recovering fixed costs. I do not recall much if any discussion or calculation of marginal cost in the context of the transmission and distribution businesses. The assumption was that the regulated price should cover efficient forward-looking costs, plus a return to existing investment, and the key question was what the forward-looking costs should be assumed to be, in their entirety and not just at the margin.

\section{$9.2 \quad$ TELRIC pricing}

This leads into the author's persuasive critique of the "problematic" nature of TELRIC ratemaking. Quite apart from any competition policy deficiencies, his concern is that "there is no analytical or empirical place to begin in pricing a theoretically most-efficient network". The exercise becomes simply "a vehicle for creating a margin between wholesale and retail rates" with a view to securing sufficient new competitive entry.

Regulation in most utility sectors has been concerned (or should have been) to provide an adequate margin to secure new entry at the retail level. Unlike in the telecommunications sector, regulation in the electricity sector has generally not been faced with the dilemma that low prices for network services will discourage new entry into those services. In the UK, regulated prices for electricity network services have always sought to encourage greater efficiency and pass the benefits to customers. Nonetheless, regulatory calculations in the UK electricity sector have never focused on a theoretically most efficient network. The focus has always been on identifying an efficient operating and investment programme for the next five years or so, given the network as it actually stands at the time of appraisal.

\subsection{What regulators should do}

The author's first proposed task is that regulators should make the legal standards better defined and more reliable over time. To this end, they could "actually define concepts like "public interest" and "just and reasonable" to provide more substance and predictability to the standards." They could also "change their focus from ex ante prescriptive rulemaking to ex post dispute-specific complaint resolution."

\footnotetext{
${ }^{39}$ Weisman $(2002,91)$.

${ }^{40}$ Weisman $(2002,93)$.
} 
It would be useful to have more discussion of this task. I do not perceive the typical competition authority or regulatory commission as keen to define its role in the abstract. Nor does it like to fetter its future discretion by extending its judgement beyond the instant case (on which it has heard evidence) to future cases of an as-yet unknown kind. I agree that ex post dispute-specific complaint resolution is a more manageable task for a commission. However, can a commission totally avoid prescribing ex ante rules if this seems a more effective way to deal with an actual or potential series of problems? Perhaps this reflects a distinction between the US precedent-based approach and the UK licensedbased approach.

The author's second proposal is that state commissions must return to recognizing their core competencies. Specifically, whereas price cap plans recognized the institutional limitations of the commissions and the past failures of rate of return regulation, their "light touch" value is being obscured by the 1996 Act's return to a regulation-intensive pricing model.

I tend to agree with this. Nevertheless, it is interesting that in India and other developing countries it is perceived that setting multi-year tariffs based on price caps would be more difficult than approving proposed tariffs on an annual basis. There has therefore been some resistance to a shift to price caps on the basis that commissions there would not have the expertise and resources to carry out the examination and secondguessing of costs necessary to set these price caps.

The author presumably has in mind that a cap for any period $t$ (if required at all) could simply be set equal to average cost at the end of the previous period $t-1$, with no need to forecast future costs in detail. Customers then benefit in the next period $t+1$ from the observed reduction in costs by the end of period t. This works as long as such a price cap provides sufficient incentive to reduce costs without the risk of excessive or inadequate profits during period t. As noted above, certain regulated businesses are more suited to such price caps than others.

The author's third suggestion is that "state commissions can broaden deregulation so that their ex ante prescription of pricing or earnings or terms and conditions melts away completely". They can then concentrate on resolving complaints, which they can do with comparative advantage in expertise, speed, and principle.

I agree with this. Unfortunately not all regulators feel the same urge to disengage. Or if they do, they are so pressed by customer groups, competitors, parliamentary committees, governments and others to retain price caps and other controls that they judge it prudent not to melt away completely, or not just yet.

\section{Concluding comment}

These papers have provided insights into why and how incentive regulation has been adopted in the US utility sector, particularly telecommunications. They have explored controversial issues like TELRIC pricing. And they have discussed the outcomes, particularly with respect to quality of supply.

This paper has reviewed these papers in turn. It has adduced the UK experience of incentive regulation, particularly in the electricity sector, to evaluate, amongst other things, the reasons for development and adoption of this approach, the determinants of X setting, and the case for more advanced metering. It suggests, among other things, that price caps 
can be designed to facilitate the transition to retail competition, that a rise in complaints might be explicable in part by factors other than quality of service, that TELRIC pricing has yet to acknowledge fully the implications of time and lack of knowledge, and that a failure to recognise the impact of competition on quality and variety of service could underestimate the benefits of competition in supply. It recognises similarities and some differences between the UK experience and the accounts of regulators that have introduced incentive regulation in the US.

It is rewarding to see a change in approach compared to economists' discussions of regulation some decades ago. The blackboards are being put away. Here are economists dealing with reality, with a proper appreciation of incentives.

\section{References}

Ai, C. and D. E. M. Sappington (2002) "The impact of state incentive regulation on the US telecommunications industry," Journal of Regulatory Economics, 22: 133 - 160.

Bartle, I. (ed.) (2003) The UK Model of Utility Regulation, CRI Proceedings 31, University of Bath, September.

Baumol, W. J. (1971) "Optimal depreciation policy: pricing the products of durable assets," Bell Journal of Economics and Management Science, 2: 638 - 656.

Baumol, W. J. (2001) "Economically defensible access pricing, competition and preservation of socially desirable subsidy," Utilities Policy, 10: 151-159.

Comnes, G. A., S. Stoft, N. Greene and L. J. Hill (1995) Performance-Based Ratemaking for Electric Utilities: Review of Plans and Analysis of Economic and Resource-planning Issues, Vol I, Berkeley: Lawrence Berkeley National Laboratory, University of California, November.

Crew, M. A. and P. R. Kleindorfer (1996) "Price Caps and Revenue Caps: Incentives and Disincentives For Efficiency" in Pricing and Regulatory Innovations Under Increasing Competition, ed. Michael A. Crew, Kluwer Academic Publishers, 39-52.

Donald, S. G. and D. E. M. Sappington (1997) "Choosing among regulatory options in the United States telecommunications industry," Journal of Regulatory Economics, 12: 227244.

Hausman, J. A. and J. G. Sidak (1999) "A consumer-welfare approach to the mandatory unbundling of telecommunications networks," The Yale Law Journal, 109: 417-505.

Hausman, J., T. Tardiff and A. Belinfante (1993) "The Effects of the Breakup of AT\&T on Telephone Penetration in the U.S.," American Economic Review, Papers and Proceedings, 83: $178-184$.

Joskow, P. L. and R. Schmalensee (1986) "Incentive regulation for electric utilities," Yale Journal on Regulation, 4: 1-49. 
Kridel, D. J., D. E. M. Sappington and D. L. Weisman (1996) "The effects of incentive regulation in the telecommunications industry," Journal of Regulatory Economics, 9: 269306.

Littlechild, S. C. (1970) "Marginal cost pricing with joint costs", Economic Journal, LXXX: 223-235.

Littlechild, S. C. (1983) "The Regulation of British Telecommunications' Profitability" London: Department of Industry, reprinted in The UK Model of Utility Regulation, ed. I. Bartle, CRI Proceedings 31, University of Bath, September.

Littlechild, S. C. (2002a) Regulators, Competition and Transitional Price Controls: A critique of price restraints in electricity supply and mobile telephones, Institute of Economic Affairs Occasional Paper, www.iea.org.uk, 19 February.

Littlechild, S. C. (2002b) "Competition in Retail Electricity Supply," Journal des Economistes et des Etudes Humaines, 12: 353-376.

Littlechild, S. C. (2003a) "Wholesale Spot Price Pass-Through," Journal of Regulatory Economics, 23: 61-91.

Littlechild, S. C. (2003b) "Transmission regulation, merchant investment, and the experience of SNI and Murraylink in the Australian National Electricity Market", 12 June, mimeo, http://www.ksg.harvard.edu/hepg.

Littlechild, S. C. (2003c) "Consumer Participation in Regulation: stipulated settlements, the consumer advocate and utility regulation in Florida", Market Design 2003 Conference, Stockholm, 17 June, Proceedings, www.elforsk-marketdesign.net.

Littlechild, S. C. (2003d) "The birth of RPI-X and other observations" in The UK Model of Utility Regulation, ed. I. Bartle, CRI Proceedings 31, University of Bath, September. 2003.

National Audit Office (2002) Pipes and Wires, Report by the Comptroller and Auditor General, HC 723 Session 2001-2002, London, 10 April.

Peltzman, S. (1989) "The economic theory of regulation after a decade of deregulation," Brookings Papers on Economic Activity: Microeconomics, Washington DC: Brookings Institution, 1-41.

Weisman, D. L. (2000) "The (in)efficiency of the "efficient-firm" cost standard," Antitrust Bulletin, 45: 195-211.

Weisman, D. L. (2002) "Did the High Court reach an economic low in Verizon v. FCC?" Review of Network Economics, 1: 90-105. 